\title{
A test site for the magnetic detection of buried steel drums
}

\author{
Marco Marchetti, Massimo Chiappini and Antonio Meloni \\ Istituto Nazionale di Geofisica, Roma, Italy
}

\begin{abstract}
An environmental investigation test site for the application of magnetic techniques to detect buried steel drums was performed in Central Italy. A magnetic survey was carried out on the area of the test site, where 12 steel drums had previously been buried. The survey was performed by means of a proton precession magnetometer for total field measurements in single sensor as well as in gradiometer configurations. The experiment has led to the definition of the magnetic signature of vertically oriented drums buried at $4.5 \mathrm{~m}$ below ground level. A digitally enhanced magnetic anomaly map was then produced, allowing further modelling procedures. Data reduction, processing procedures and results are presented.
\end{abstract}

Key words environmental geophysics - test site magnetic anomalies

\section{Introduction}

Environmental geophysics is increasingly being involved in the development of new methods of diagnosis. Geophysical techniques can in fact provide non-invasive means to detect the presence of buried waste containers and discarded objects. The investigations are generally in close coordination with the aims of the national and international environmental policy objectives.

The detection and quantitative estimate of the mass of ferromagnetic buried material play an essential role in investigations addressed to environmental subjects. In this frame, the magnetic approach is very helpful, especially in cases of high signal-to-noise ratio.

As specifically concerns the need to identify buried waste containers and discarded objects, in this short note we will discuss the applica-

Mailing address: Dr. Marco Marchetti, Istituto Nazionale di Geofisica, Via di Vigna Murata 605, 00143 Roma, Italy; e-mail: marchettim@ingrm.it tion of the magnetic method that was originally developed as a sensitive technique to the solution of several geophysical investigation problems (see Parkinson, 1983). In this framework, Gilkenson et al. (1992) conducted field and model studies to determine the characteristic responses of magnetic total intensity, magnetic vertical gradient, electromagnetic (EM) quadrature and EM in-phase measurements over buried drums. Pierce and DeReamer (1993), Dwyer and Johnson (1993) performed vertical magnetic gradient surveys to locate isolated buried waste drums at large sites in California and New Jersey respectively. Unexploded ordnances were located by Foley (1994) while searching for buried waste containers in New Mexico by means of a towed array of magnetometers. Dahlin and Jeppsson (1995) in Southern Sweden investigated the existence and location of buried metal objects using magnetometry, dual loop EM and electrical resistivity.

The Geomagnetism Department of ING has recently built an environmental investigation test site to model the magnetic signature of metallic objects. Data acquisition, interpretation and modelling has been addressed in this test site and reported in the following. 


\section{Magnetic field anomalies}

The Earth is permeated with a magnetic field that originates in the Earth's fluid outer core as a consequence of magnetohydrodynamic processes. The combination of a relatively fast convective motion of the very high electrical conductive core material (mainly composed of iron and small percentage of sulphur) with Earth's rotation effects, generates a magnetic field that, in its poloidal part, penetrates the mantle and the crust (Parkinson, 1983; Merrill et al., 1996).

As is known, only the Earth's crust can interact significantly with the primary magnetic field mainly by means of natural remanence brought by ferromagnetic minerals at temperatures lower than Curie point. The effect of this contribution gives rise to the so-called crustal magnetic anomalies generally detected by means of local and, to some extent, regional surveys. On the local scale geological structures such as iron rich mineral ores or other magnetic structures can easily be revealed.

In this framework non natural magnetic anomalies of generally very shallow origin (order of tens of meters at maximum) can also be detected in very local, low spacing magnetic surveys. For this reason steel rich bodies like wrecked strips, buried bombs and mines can be detected by means of magnetic field surveys. The Earth's magnetic field shows spatial variations, like those above mentioned, as well as time variations. The latter have time scales that range from a few seconds or minutes to a few years. They can occur during magnetic field surveys superimposing on spatial magnetic anomalies and modifying their shape. A correct magnetic survey, even on very local scale, must take into consideration the effect of magnetic time variations and then, by independently monitoring with another magnetometer, use this information to correct the data.

\section{The test site and data analysis}

An assemblage of 12 new 55 gallon steel drums were employed in the test. After a careful choice, a site was chosen in the Apennines in Central Italy at $1400 \mathrm{~m}$ a.s.l., where a mag- netic base station had previously been installed to monitor the daily geomagnetic activity. The site is characterized by fluvial-glacial deposits consisting of conglomerates in a silt-sandy matrix which can be considered a null, or very low, magnetic matrix. The drums, vertically oriented, were thus buried with their top surface at a depth of $4.5 \mathrm{~m}$ below ground level (fig. 1) in order to simulate a real case of hiding drums (e.g., containing toxic waste). The resulting buried body had the rough shape of a prism $88 \mathrm{~cm}$ high, having a $2 \times 3 \mathrm{~m}$ base with its longer side $\mathrm{E}-\mathrm{W}$ oriented. A rectangular area of $22 \times 25 \mathrm{~m}$ was then surveyed by means of a proton precession magnetometer in gradiometric configuration.

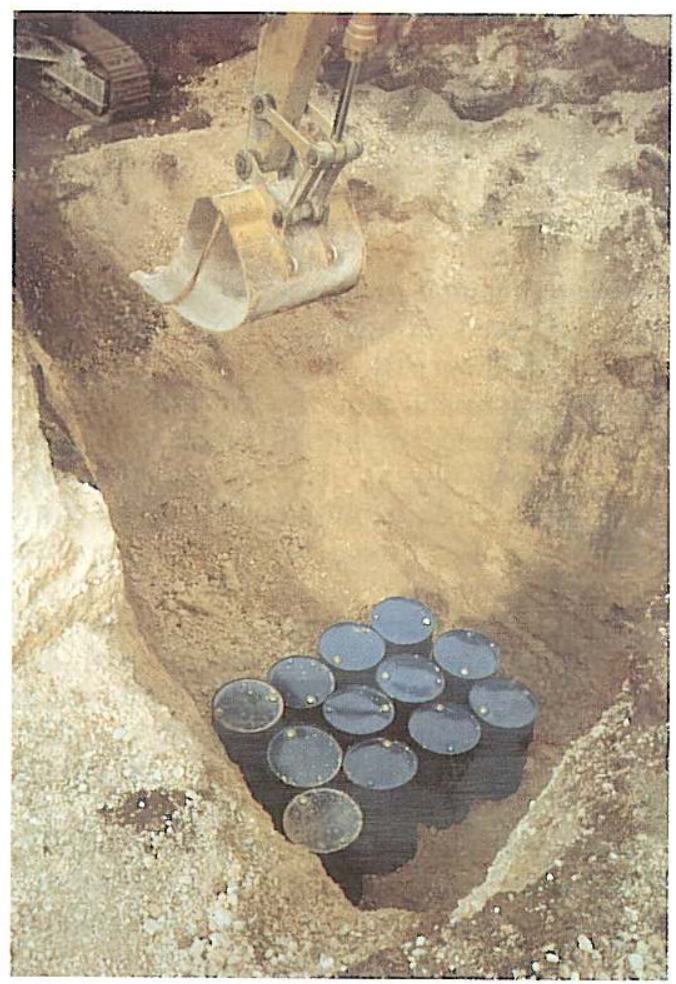

Fig. 1. Preparation of the test site; the drums were buried, vertically oriented, with their top surface at a depth of $4.5 \mathrm{~m}$ below ground level. 


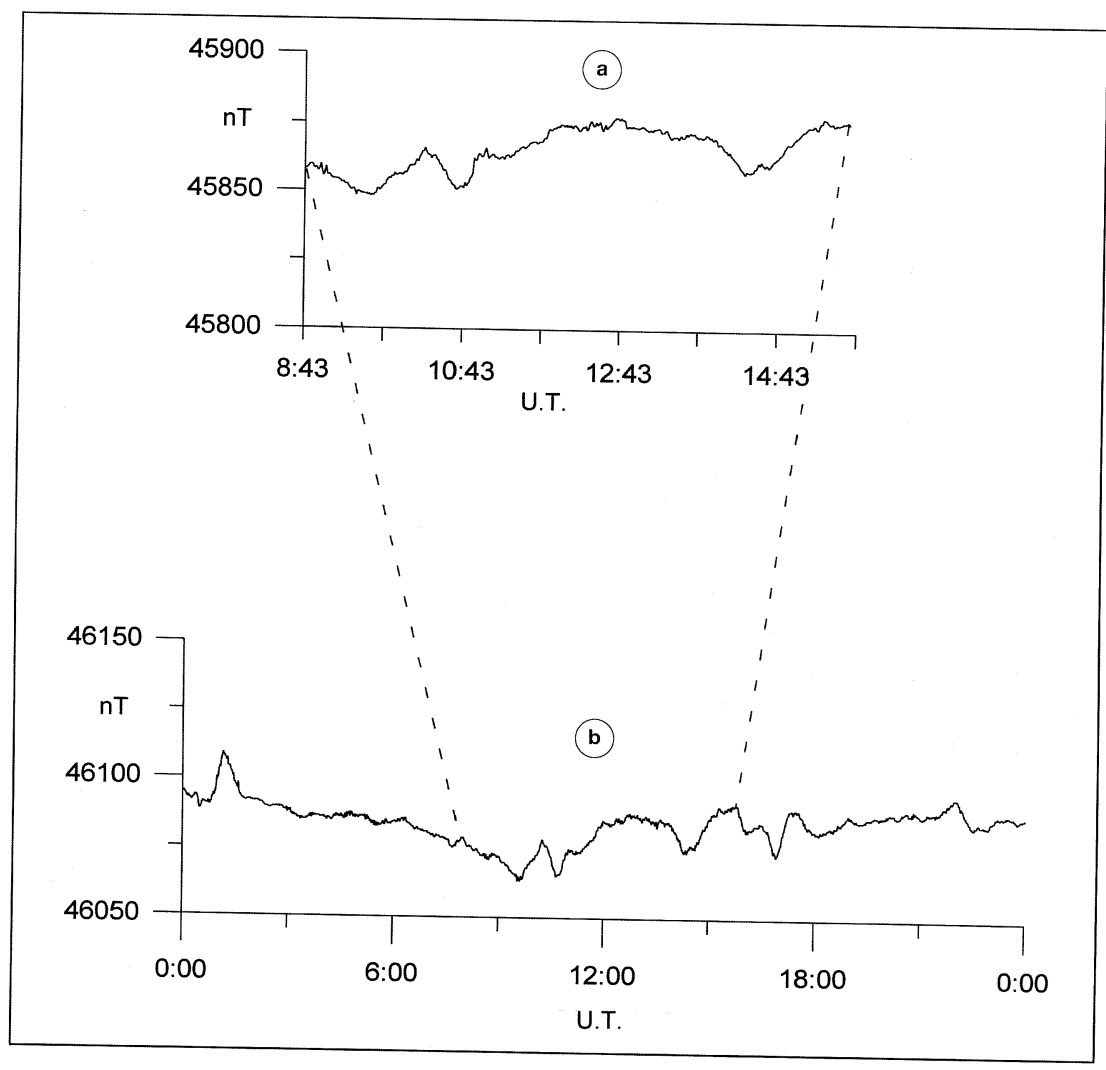

Fig. 2a,b. a) Time variations of the total intensity field recorded every minute at the location of the environmental investigation test site, during the measurements; b) magnetogram of 31st July 1996, day of the experiment, showing the total intensity of the Earth's magnetic field recorded at L'Aquila Geomagnetic Observa-
tory.

The size of the area was chosen according to a preliminary survey which was conducted to identify the edges of the area showing no significant field variations. The distances to the ground level of the bottom and top sensors were $75 \mathrm{~cm}$ and $150 \mathrm{~cm}$ respectively. The survey was performed along profiles spaced $1 \mathrm{~m}$ each other at a sampling space interval of $1 \mathrm{~m}$, while a magnetic base station was continuously running at a sampling rate of $1 \mathrm{~min}$. The time window during which the measurements were carried out is shown in fig. $2 a$, while fig. $2 b$ shows the magnetogram of the whole day (7/31/1996) recorded at L'Aquila Observa- tory. A low magnetic activity appears to characterize the day.

Each profile was corrected for the magnetic diurnal variation. Then a constant value as a magnetic base level was subtracted to all measurements, thus obtaining two level anomaly maps for both the bottom and the top sensors. A digitally enhanced shaded relief magnetic anomaly map of the top sensor is shown in fig. 3, where contour interval is $10 \mathrm{nT}$. The total field recorded with the top sensor was selected. The bottom sensor, being closer to the magnetic source, showed a slightly higher noise superimposed to the signal. The magnetic ano- 

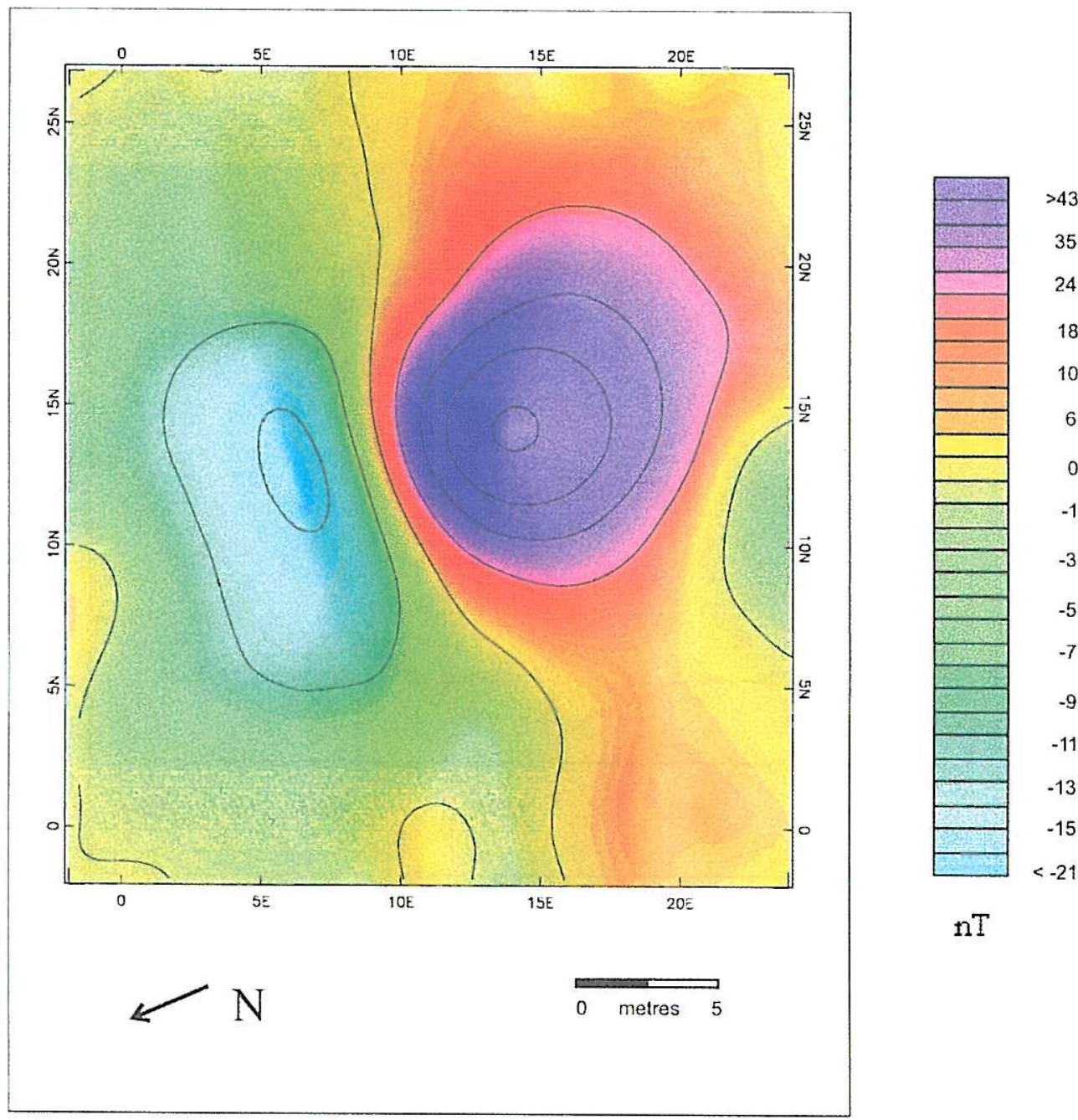

Fig. 3. Shaded relief magnetic anomaly map of the total intensity of the magnetic field recorded by the top sensor. Contour interval is $10 \mathrm{nT}$.

maly produced is typically dipolar, with well defined maximum (43 $\mathrm{nT}$ ) and minimum $(-26 \mathrm{nT})$ whose main axis is N-S oriented.

The vertical gradient map is displayed in fig. 4 , with contour interval equal to $5 \mathrm{nT} / \mathrm{m}$; the gradient ranges between $-18 \mathrm{nT} / \mathrm{m}$ and $23 \mathrm{nT} / \mathrm{m}$. Since the magnetic anomaly produced by the barrels is well defined fitting the whole survey area and signal to noise ratio is rela- tively high, then the magnetic vertical gradient map does not furnish significant further information for the single sensor analysis. The bodies used in the test site buried at a greater depth, would produce an analogous but less intense magnetic anomaly, as shown in fig. 5, where the map is upward-continued to $7 \mathrm{~m}$. The peak to peak values of the obtained anomaly are $+6 \mathrm{nT}$ and $-1.5 \mathrm{nT}$. 


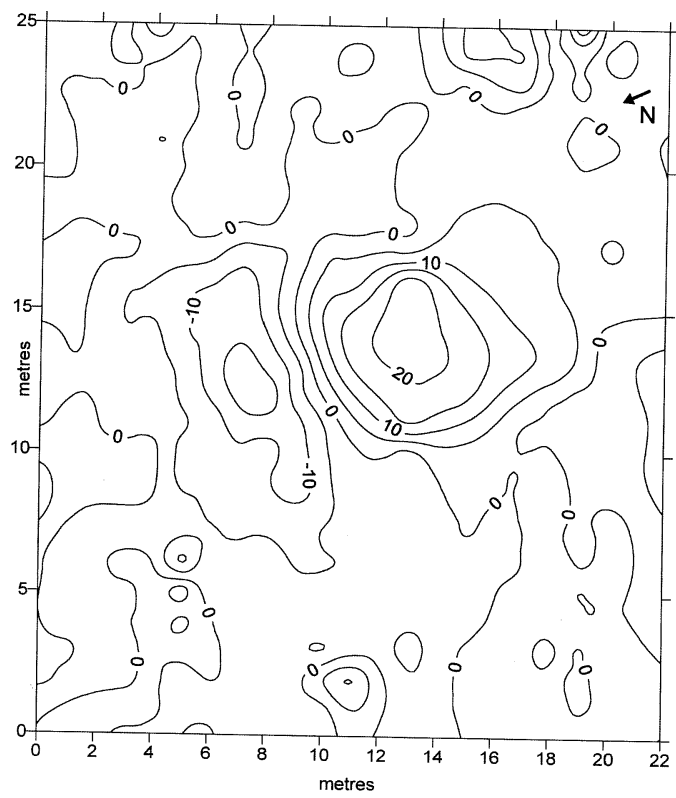

Fig. 4. Vertical gradient magnetic map; contour interval is $5 \mathrm{nT} / \mathrm{m}$.

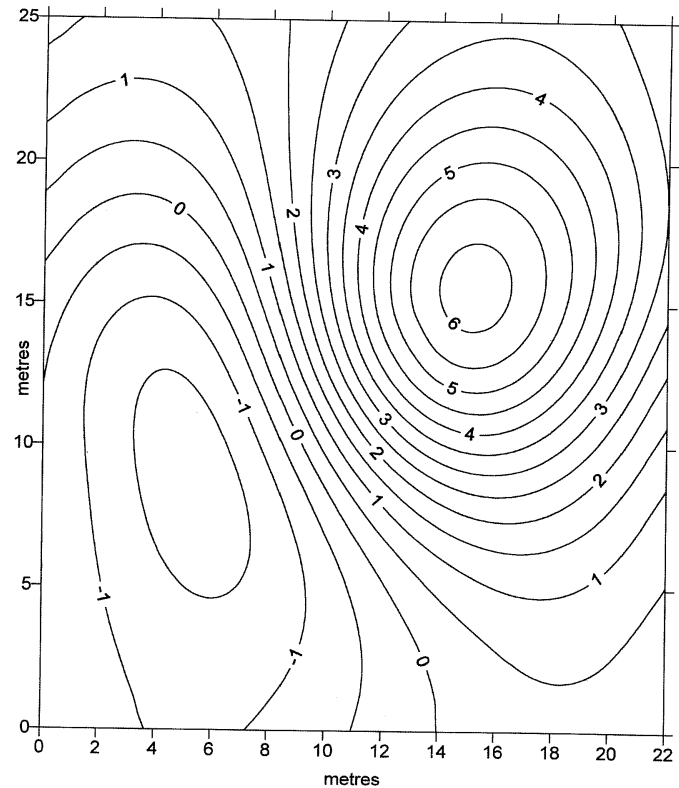

Fig. 5. Upward continued magnetic anomaly map. A distance of $8.5 \mathrm{~m}$ from ground level is supposed. Contour interval is $0.5 \mathrm{nT}$.

\section{Magnetic interpretation and conclusions}

Since the aim of the present paper is to realise a sort of reference model for environmental observers and investigators using magnetic techniques, some simple magnetic modelling was undertaken on the basis of methods developed mainly for geological structures (Blakely, 1996).

In the present study several problems emerge and make this case more difficult to model than a natural case, for example a strong remanent magnetisation with unknown direction, possible susceptibility anisotropy and demagnetization effects. The approach reported in this study is only a first attempt made in order to fit the experimental data. Magnetic modelling of underground structures is based on 2D1/2 approach (Rasmussen and Pedersen, 1979; Won and Bevis, 1987), the known parameters being the size of the body, its depth and magnetic anomaly values.

A N-S profile across the anomaly was extracted from the map and then a suitable interpretation attempted. The unknown was mainly the magnetic susceptibility. A detailed laboratory analysis by Ravat (1996) has shown that in new unrusted drums, the induced component is much larger than the remanent component and the volume susceptibility ranges around 21-28 SI units.

A body with the same size as the 12 barrels and at the same depth was modelled, obtaining the calculated profile shown in fig. 6 . A value of magnetic susceptibility of 0.038 (cgs units) was assigned to the body; slight variations of this value do not significantly affect the differences between the observed and the calculated values along the profile. Figure 6 also shows how the fit of the negative part of the profile does not seem to be improved by varying the value of susceptibility in the calculated model. The introduction of a positive value of remanent magnetisation makes a better fit possible at the end part of the profile (fig. 7).

The introduction of a remanent magnetization and its direction can be relevant in the case of ferromagnetic objects since in this case both induced and remanent magnetizations can contribute to produce a single magnetic 

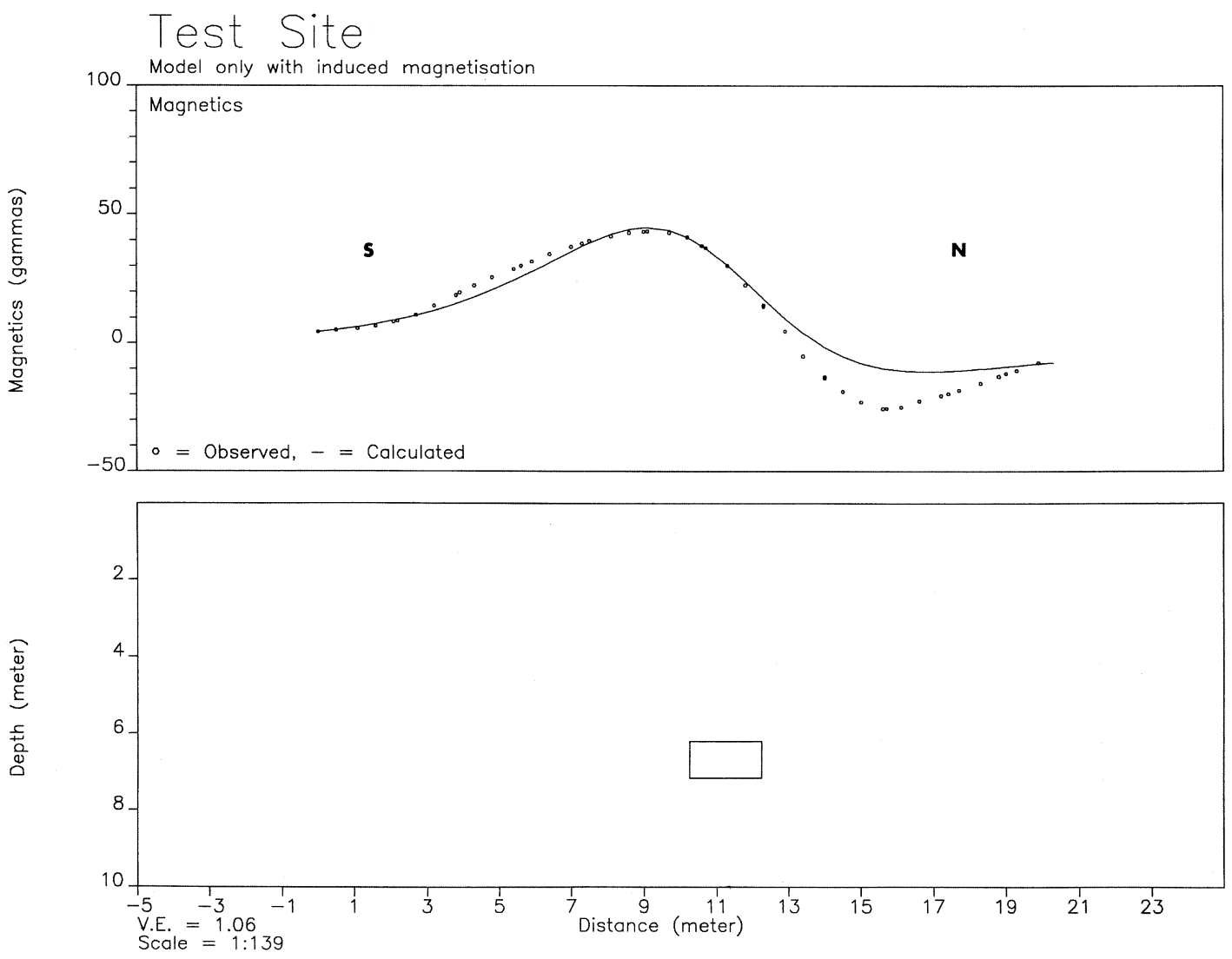

Fig. 6. N-S profile (circles) along the main axis of the anomaly of fig. 3; a model of anomaly produced by the body shown in the lower part of the figure, calculated by using a $2 \mathrm{D}^{1 / 2} \mathrm{2}$ technique is superimposed to the measured profile. No remanent magnetisation is considered in the model.

anomaly. In extreme cases (very hard steel) the remanent magnetization can reach 5 to 10 times the value of induced magnetization (Ravat, 1996).

Modelling magnetic markers with both contributions is generally more difficult. In our case however the assemblage of steel drums can be viewed as the combination of single individual permanent magnetization that partly compensate each other leaving almost only the induced part (theoretically in the limit of a very large number of drums completely cancelling the remanent contribution).
As administrators become more familiar with geophysical investigation techniques, the role of geophysics in the determination and location of environmental hazards is evolving. The described magnetic survey over a test site has allowed to determine the magnetic signature of 12 new (unrusted) buried steel drums. Subsequent modelling has shown the magnetic response of the metallic object at a different depth. Environmental investigators have now a case study for reference during magnetic surveys for the detection of metallic objects. 

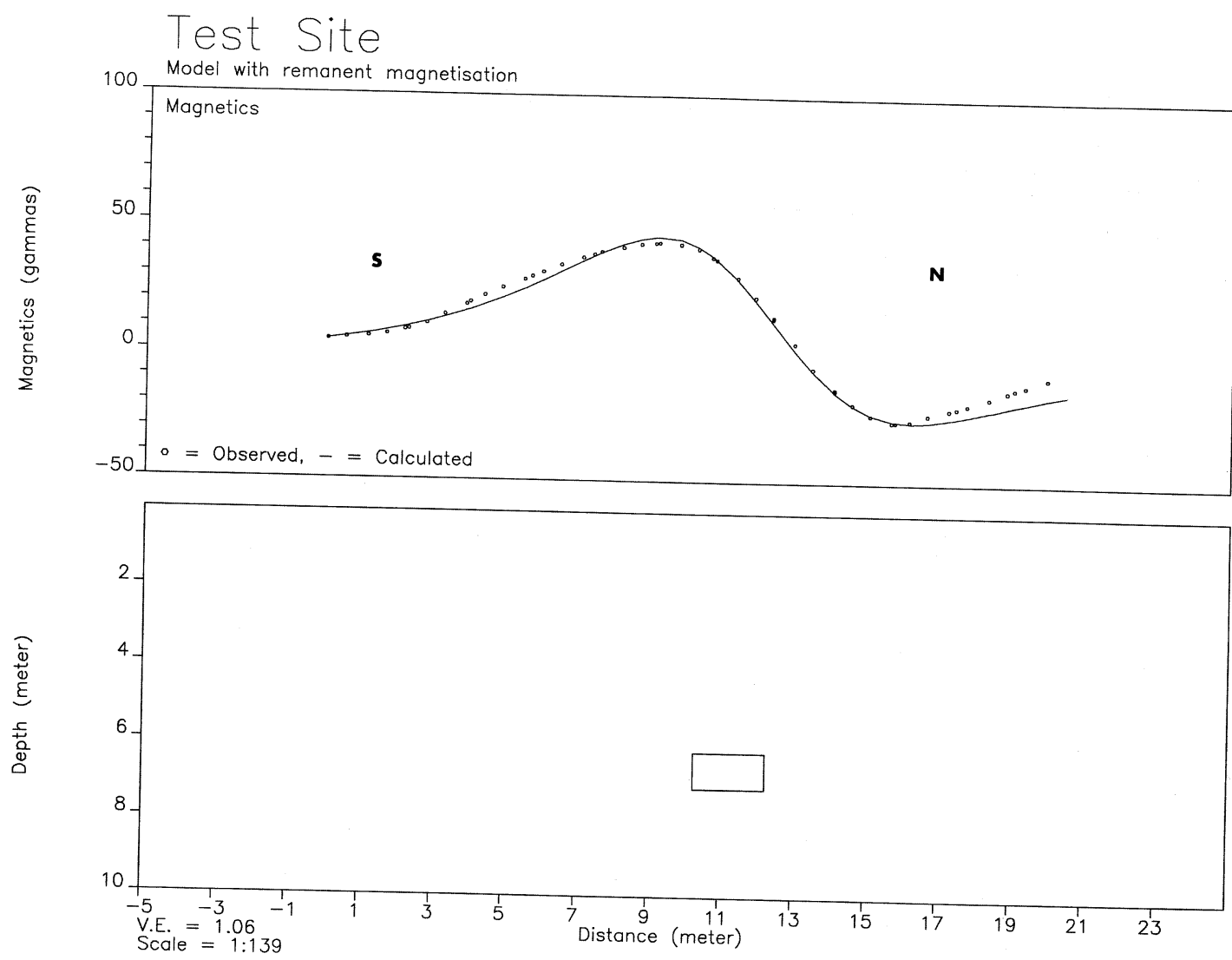

Fig. 7. As fig. 6 but introducing a positive value of remanent magnetisation in the model.

\section{Acknowledgements}

The useful suggestions of Dr. Cinti of ESSO S.p.A. were much appreciated. The authors wish to thank the State Forest Corps and Mr. Oddis of the Technical Office of Comune di Roccaraso. The research was supported by Istituto Nazionale di Geofisica.

\section{REFERENCES}

Blakely, R.J. (1996): Potential Theory in Gravity and Magnetic Applications (Cambridge University Press).

DAHLIN, T. and H. JEPPSSON (1995): Geophysical investigation of a waste deposit in Southern Sweden, in Proceedings of the Symposium on the Application of Geo- physics to Engineering and Environmental Problems, April 23-26, 1995, Orlando, Florida, edited by R.S. BELL, 97-105.

DWYER, M.K. and D. JoHNSON (1993): Using surface geophysics to locate buried drums at an industrialized Superfund site in New Jersey, in Proceedings of the Symposium on the Application of Geophysics to Engineering and Environmental Problems, April 18-22, 1993, San Diego, California, edited by R.S. BELL and C.M. LEPPER, 245-257.

FOLEY, J.E. (1994): STOLMS(TM) magnetic survey at Sandia National Laboratory Technical area 2, in Proceedings of the Symposium on the Application of Geophysics to Engineering and Environmental Problems, March 27-31, 1993, Boston, Massachusetts, edited by R.S. BELL and C.M. LEPPER, 195-207.

GILKENSON, R.H., S.R. GORIN and D.E. LAYMON (1992): Application of magnetic and electromagnetic methods to metal detection, in Proceedings of the Symposium on the Application of Geophysics to Engineering and En- 
vironmental Problems, April 26-29, 1992, Oakbrook, Illinois, edited by R.S. BELL, 309-328.

Merrill, R.T., M.W. McElhinny and P.L. MCFAdDEN (1996): The Magnetic Field of the Earth (Academic Press), pp. 507.

PARKInson, W.D. (1983): Introduction to Geomagnetism (Scottish Academic Press), pp. 433.

Pierce, D. and J. DeReamer (1993): Geophysical investigation for buried drums: a case study, in Proceedings of the Symposium on the Application of Geophysics to Engineering and Environmental Problems, April
18-22, 1993, San Diego, California, edited by R.S. BELL and C.M. LEPPER, 229-244.

RAVAT, D. (1996): Magnetic properties of unrusted steel drums from laboratory and field-magnetic measurements, Geophysics, 61 (5), 1325-1335.

Rasmussen, R. and L.B. Pedersen (1979): End corrections in potential field modeling, Geophys. Prospec., 27, 749-760.

WoN, I.J. and M. BEVIS (1987): Computing the gravitational and magnetic anomalies due to a polygon: algorithms and Fortran subroutines, Geophysics, 52, 232-238. 